Case Report

\title{
Glomus Tumor: “A-Not-So-Rare” Cause of Chronic Shoulder Pain-A Case Report and Literature Review
}

\author{
Luís Vieira $\left(\mathbb{D}\right.$, Pedro Pereira $\left(\mathbb{D}\right.$, Bernardo Nunes $\mathbb{D}^{D}$, Rui Matos $\mathbb{D}^{\mathbb{D}}$, António Sousa $(\mathbb{D}$, \\ and Manuel Ribeiro da Silva
}

Centro Hospitalar Universitário São João, Portugal

Correspondence should be addressed to Luís Vieira; luisppvieira@gmail.com

Received 1 December 2020; Accepted 10 May 2021; Published 27 May 2021

Academic Editor: Akio Sakamoto

Copyright (C) 2021 Luís Vieira et al. This is an open access article distributed under the Creative Commons Attribution License, which permits unrestricted use, distribution, and reproduction in any medium, provided the original work is properly cited.

Case. A 61-year-old male presented with chronic shoulder pain resistant to conservative treatment. Imaging identified a nodular lesion in the deltoid muscle, which histology after resection identified as a glomus tumor. After surgery, the patient became asymptomatic and at 4-year follow-up has not shown signs of recurrence. Conclusion. Glomus tumors around the shoulder should be considered when investigating chronic shoulder pain, as they are more common than thought. Despite being elusive, when diagnosed, excellent outcomes may be expected, with surgery resection being curative.

\section{Introduction}

Glomus tumors are benign soft tissue neoplasms of vascular origin [1]. These tumors are classically located under the fingernail beds [2], but extradigital locations are being reported more frequently [3]. While still uncommon, atypical locations of glomus tumors may be debilitating injuries and prove to be cumbersome for the orthopedic surgeon [4].

In this paperwork, we present a rare case of chronic shoulder pain caused by a glomus tumor in the deltoid muscle. As these lesions appear to be more prevalent than assumed, we also present a compilation of all the published cases and a short literature review.

\section{Statement of Informed Consent}

The patient was informed that data concerning the case would be submitted for publication, to which he consented.

\section{Case Report}

A 61-year-old right-handed male was referred to our department presenting shoulder pain for 12 months, without any known trigger event. The patient described a dull intermittent right shoulder pain, reporting acute exacerbations and tenderness. His complaints persisted despite medical treatment, including physiotherapy and long-standing medication with oral NSAIDs.

During physical examination, there were no visible asymmetries between the shoulders and the patient exhibited no inflammatory signs. The neurologic and vascular examination of the right upper limb was normal. The shoulder range of motion and strength was preserved and painless. There were no evident or palpable masses, but the patient presented trigger-point tenderness at the posterolateral surface of the right shoulder. 
Plain radiographs were normal (Figure 1). Ultrasonography of the right shoulder denoted a hypoechoic nodular formation in the point of tenderness, measuring $13 \mathrm{~mm}$ (Figure 2). Magnetic Resonance Imaging (MRI) confirmed the presence of a well-limited oval-shaped mass located in the posterior fibers of the right deltoid muscle, measuring $25 \times 10 \times 6 \mathrm{~mm}$, which was hypointense in T1 and hyperintense in T2-weighted images and exhibited strong enhancement with contrast (Figures 3 ).

It was decided to perform an excisional biopsy of the lesion. Under general anesthesia, the patient was placed in 30 degrees left-lateral position and a $5 \mathrm{~cm}$ incision was made directly over the point of tenderness which had been priory marked. Surgical exploration identified a well-limited nodular lesion between the posterior fibers of the deltoid muscle, which was completely excised (Figures 4(a) and 4(b)).

The patient was discharged in the next day after surgery and presented pain-free by the time of stitch removal.

Gross examination of the specimen revealed a brownish nodular mass with $10 \times 10 \times 6 \mathrm{~mm}$ in size, while microscopic examination showed a well-limited lesion formed by ovoid epithelial cells without signs of atypia. No mitoses were observed. The lesion displayed a rich vascular network. Marginal excision was confirmed. Immunohistochemical staining was positive for expression of actin (alpha-SMA). These findings were compatible with the diagnosis of glomus tumor (Figures 5(a)-5(c)).

The patient did not undergo any other treatment besides surgical excision of the lesion.

After 4 years of follow-up, the patient is asymptomatic and showing no clinical or imagiological evidence of local or systemic recurrence.

\section{Discussion}

Glomus tumors are vascular benign neoplasms [1, 5], arising at the glomus bodies, a specialized arteriovenous anastomosis which controls blood flow to the skin and thereby regulating temperature at the extremities [6].

Despite being widely scattered, glomus bodies are far more frequent in the digits, palms, and soles of feet [7], with $70 \%$ taking place in the hand and $50 \%$ of these arising in the subungual region $[2,8]$. Nevertheless, they can be found anywhere in the body [9].

In general, glomus tumors represent $1-6 \%$ of all soft tissue tumors [4] and 1-5\% of all hand tumors [10]. They seem more prevalent between the third and fifth decades of life and do not seem to show gender predilection [11]; however, subungual locations seem somehow more prevalent in females [1]. Overall, glomus tumors are lonely lesions [4] but may present as multiple tumors in up to $10 \%$ of patients [9].

Extradigital locations seem less rare than what was previously believed $[3,4]$. Other locations in the upper limb are the most common [4], but there have been reported cases of ectopic glomus tumor in the trunk, lower body, and even viscera $[1,3,12]$.

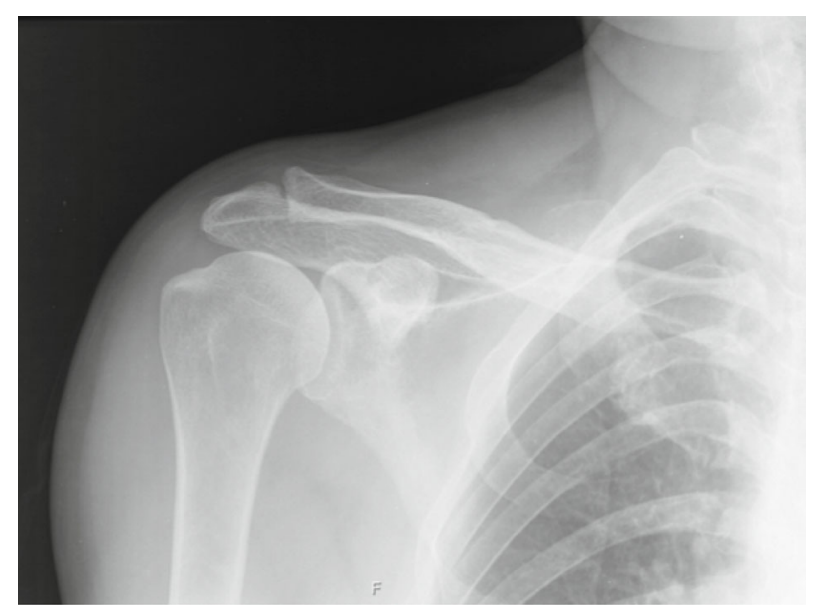

FIgURe 1: Anteroposterior radiograph of the right shoulder. The radiograph is normal.

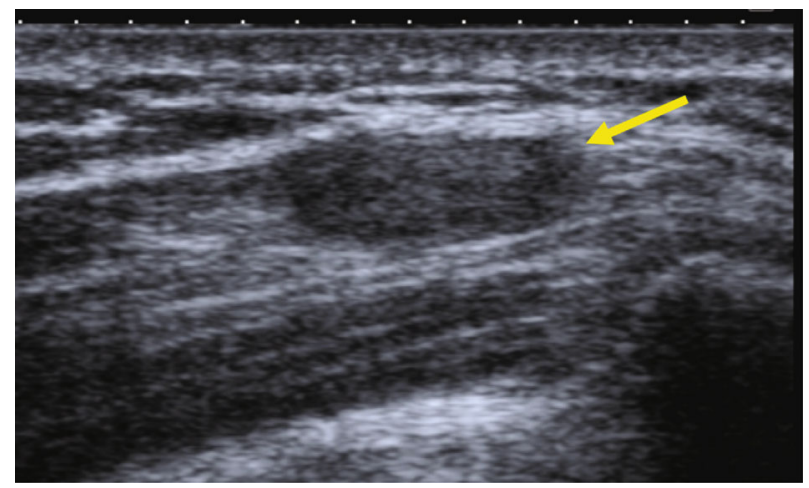

FIGURE 2: Ultrasonography of the right shoulder identified a hypoechoic nodular formation (yellow arrow) in the posterior deltoid, with approximately $8 \times 10 \times 13 \mathrm{~mm}$ in size.

Glomus tumors are generally small lesions $(<1 \mathrm{~cm}$ in diameter) [12] but particularly around the shoulder can show greater dimensions, with reported cases of lesions as big as $5 \mathrm{~cm}$ in diameter [13]. When superficial, they can be identified on inspection as they show a distinctive blue-red coloration $[12,14]$.

To our knowledge, this is the $4^{\text {th }}$ case of a glomus tumor located in the deltoid muscle $[6,15,16]$. This paper is also currently the most comprehensive compilation of glomus tumors around the shoulder, gathering all known 23 currently published cases in the English literature (Table 1).

Extradigital locations impose true diagnostic challenges [17] and may be responsible for chronic pain and timeconsuming investigation [4], often causing distress to the patients who are not uncommonly misdiagnosis with psychiatric illness $[3,14,18]$. In a series by Schiefer et al., glomus tumor was considered in the initial differential diagnosis in only $9 \%$ of cases [3]. Concerning the specific location of glomus tumors around the shoulder, the literature has been rich in cases in which diagnosis was delayed for several years, even decades $[6,17,19-21]$. These patients are usually thought to suffer from more common pathologies such as 


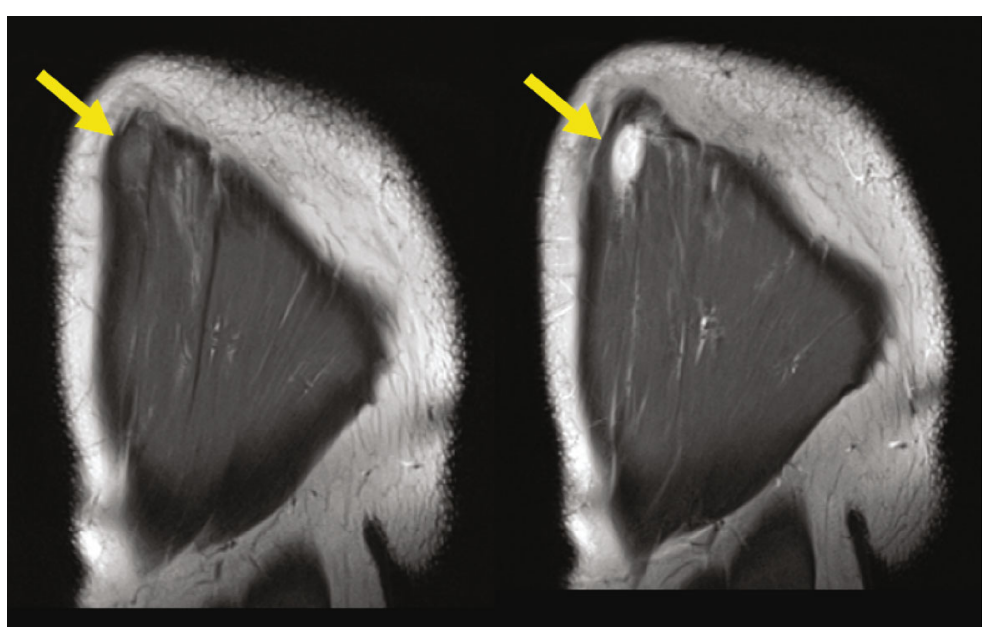

(a)

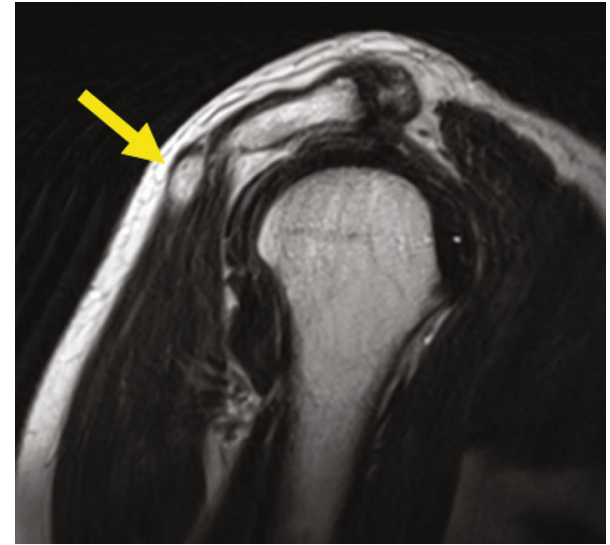

(b)

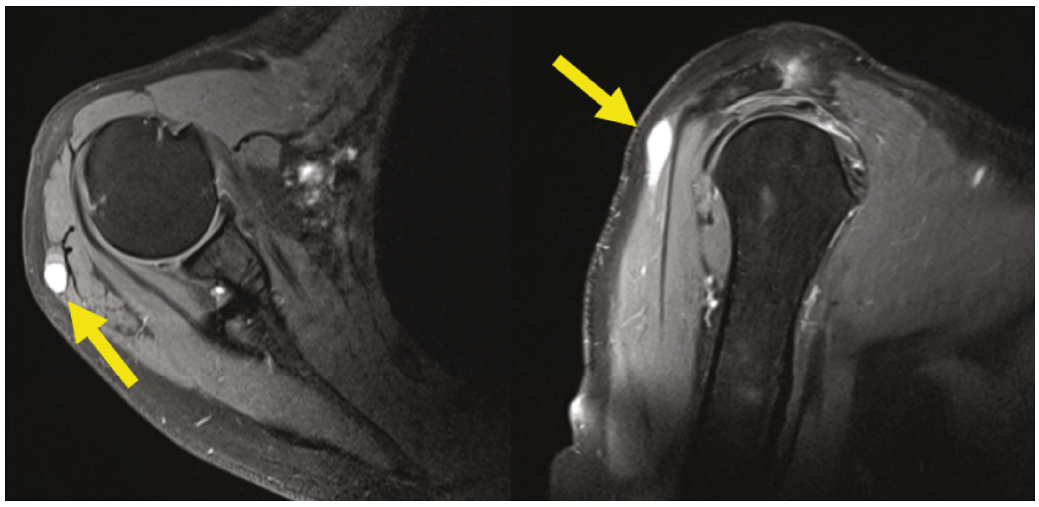

(c)

FIGURE 3: MRI images of the right shoulder. (a) Coronal images showing a nodular formation in the deltoid muscle (yellow arrows). The lesion is hypointense in T1 (left picture), but with strong enhancement with contrast (right picture). (b) Sagittal T2 image with turbo spin echo before contrast. The lesion appears as a hyperintense nodule (yellow arrow). (c) Axial (left) and sagittal (right) T1 images with fat suppression after contrast show a hyperintense well-limited lesion in the posterior deltoid (yellow arrows).

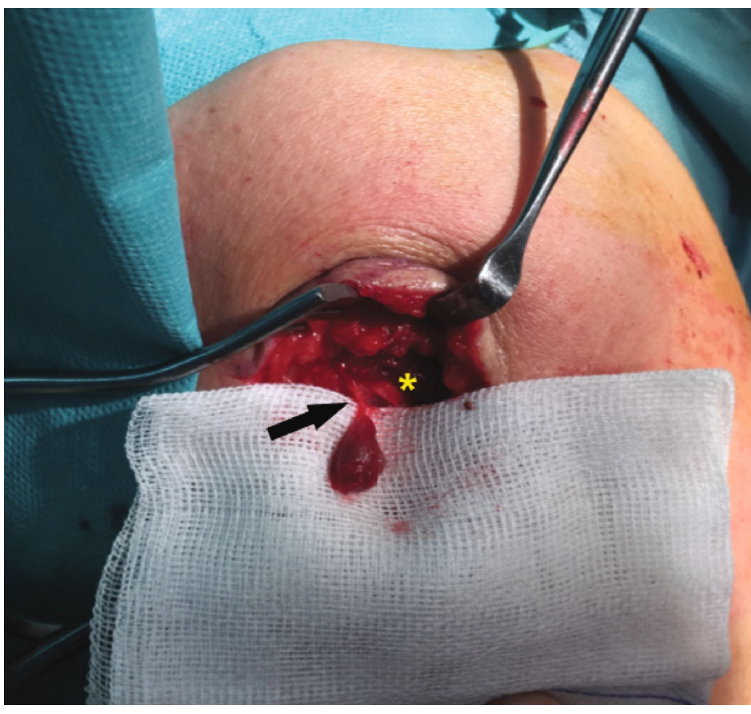

(a)

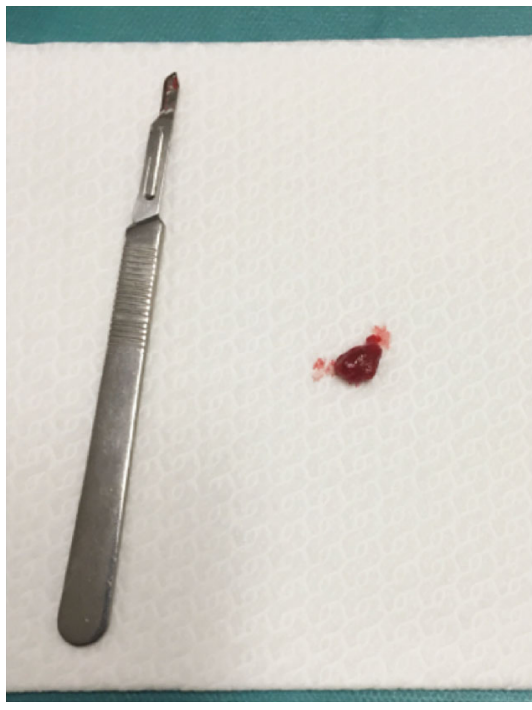

(b)

FIGURE 4: Intraoperative images. (a) Isolated tumor, primarily found in the substance of the deltoid muscle (yellow asterisk), with the tumor pedicle still intact (black arrow). (b) Resected lesion (125 mm scalpel handle with $\mathrm{n}^{\circ} 11$ blade for scale). 


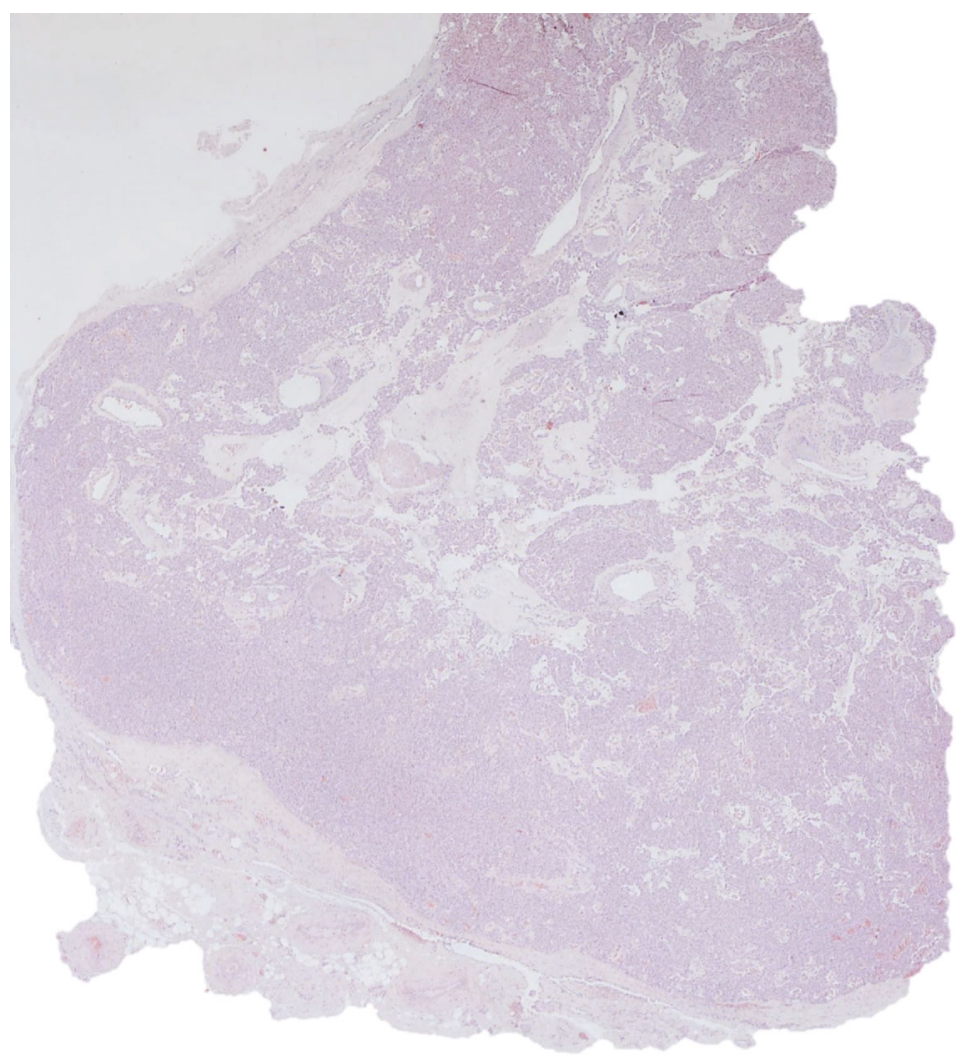

(a)

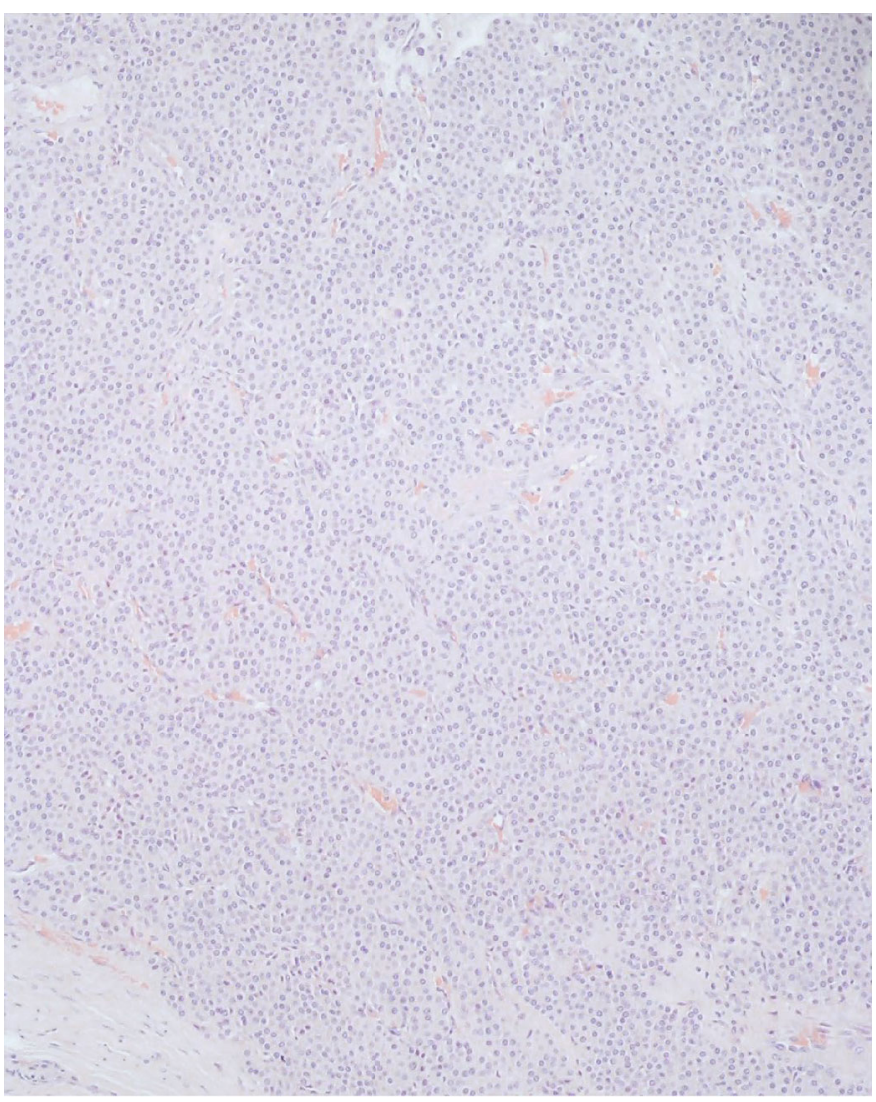

(b)

Figure 5: Continued. 


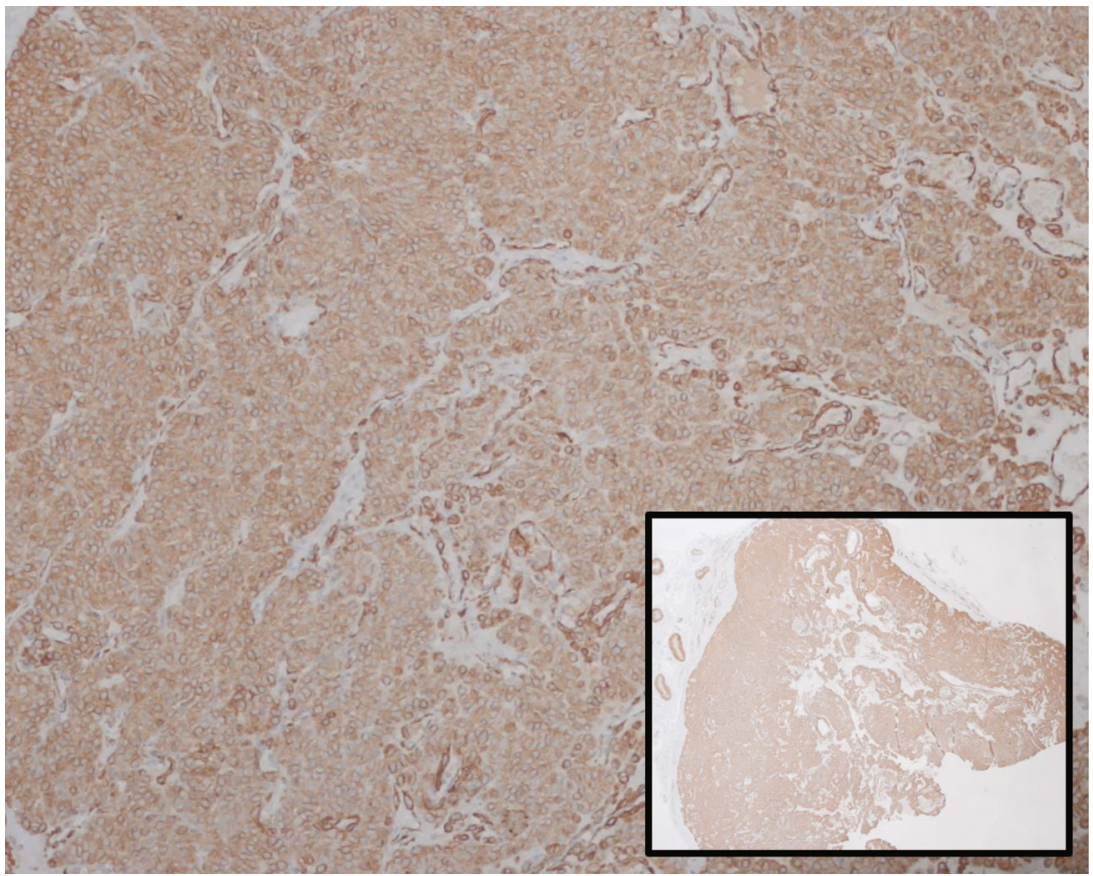

(c)

FIGURE 5: Histological images of the removed tumor. (a) Well-limited proliferative lesion, with a rich vascular network (hematoxylin-eosin; original magnification $\times 20$ ). (b) Tumor formed by ovoid, epithelial cells, without signs of atypia and showing no mitoses (hematoxylin-eosin; original magnification $\times 40$ ). (c) Diffuse expression of smooth muscle actin (alpha-SMA) in the tumor (immunohistochemcial staining; original magnification $\times 20$ (right inferior corner photomicrograph) and original magnification $\times 100$ (larger photomicrograph))

rotator cuff lesions [6], which highlights the need to have a high index of suspicion.

Glomus tumors are classic manifested by the triad of paroxysmal pain, cold hypersensitivity, and pinpoint tenderness, which when present can be considered diagnostic [7]. $63-100 \%$ of patients with glomus tumor of the hand exhibited this triad [3], which is fully present in only two cases of tumors around the shoulder [15, 17]. Some patients may present with hyperesthesia, muscle atrophy, or osteopenia of the affected area [4]. In this paper, the patient presented only paroxysms of pain and local tenderness, as did the majority of similar cases published in the literature (Table 1).

Moreover, there have been described several clinical tests which may help in the diagnosis of glomus tumors, such as the pin test of Love, the Posner test (pain induced by cold), the Hildreth ischemia test, and transillumination $[6,22]$. Nonetheless, the validity of these tests seems limited to the digits [6].

MRI can be helpful in the diagnosis of glomus tumors, which mostly exhibit low signal intensity on T1-weighted images, hyperintensity on T2-weighted images, and enhancement on T1-weighted images after gadolinium injection [23]. In addition, glomus tumors may display the very typical finding of a highsignal nidus on $\mathrm{T} 2$ circumscribed by a low-signal ring, which is not evident in all the cases though $[9,23]$.

MRI has been described to have a sensitivity of $90 \%$ for the diagnosis of glomus tumours [24], being able to detect lesions as small as $2 \mathrm{~mm}$ in diameter [23]. Nevertheless, in a setting of high index of clinical suspicion, a negative MRI should not reject the diagnosis [3]. Moreover, the specificity has been reported to be as low as 50\% [25], which, associated with the high cost of this exam compared to sonography, settles MRI as a second-line imaging modality [23].

The final diagnosis is confirmed by microscopic and immunohistochemistry examination of the lesion [17]. Histologically, these tumors have been classified accordingly to the predominant expression of glomus cells, blood vessels, and smooth muscle cells in solid glomus tumors (73\%), glomangiomas (25\%), and glomangiomyomas (8\%), respectively $[4,26]$. Immunohistochemical analysis reveals vascular and muscular phenotype, with a distinguishing and diffuse expression of $\alpha$-SMA (alpha smooth muscle actin) and a variable expression of CD34 [9].

Surgery is usually required, as conservative treatment is often unsatisfactory $[3,16,23]$. Marginal excision is normally sufficient in the treatment of these neoplasms [12, 27] without the need of adjuvant therapy [13], tough adjuvant radiotherapy may be used in the cases of incomplete resection [17, 27].

Malignization is rare [26]. Of those cases reported around the shoulder, only Rishi et al. have reported a malignant lesion [11]. Folpe et al. have described several features to determine malignancy of these neoplasms: (1) large size $(>2 \mathrm{~cm})$, (2) deep location, (3) atypical mitotic figures, (4) moderate to high nuclear grade, and (5) $\geq 5$ mitotic figures/50 HPF [26]. Based on this classification, one could argue that our case should be considered a malignant lesion, as the intramuscular location of the lesion qualifies as a deep location. However, we did not intend to perform a diagnostic biopsy before surgery and we were already aiming for 
TABLE 1: Table compiling all cases of glomus tumors around the shoulder published in English literature.

\begin{tabular}{|c|c|c|c|c|c|c|}
\hline Paper (year published) & Age & Gender & Location & $\begin{array}{l}\text { Size } \\
(\mathrm{cm})\end{array}$ & $\begin{array}{c}\text { Time until } \\
\text { diagnosis (years) }\end{array}$ & Symptoms \\
\hline Bailey (1935) [19] & 48 & Male & Lateral shoulder & 0.3 & 20.0 & $\begin{array}{l}\text { Pain, } \\
\text { tenderness }\end{array}$ \\
\hline Riveros \& Pack (1951) [28] & 40 & Female & Scapular region & 0.5 & NR & Pain \\
\hline Massey (1992) [29] & 41 & Female & Supraescapular region & 1.0 & Several & $\begin{array}{l}\text { Pain, } \\
\text { tenderness }\end{array}$ \\
\hline Heys et al. (1992) [7] & NR & NR & NR & NR & NR & NR \\
\hline Calonje and Fletcher (1995) [30] & NA & NA & Cutaneous intraneural & NA & NA & NR \\
\hline Yoshikawa et al. (1996) [20] & 35 & Female & Rotator cuff & 4.0 & 20.0 & Pain \\
\hline Roberts et al. (1999) [21] & 67 & Male & NA & 3.5 & 20.0 & $\begin{array}{l}\text { Pain, } \\
\text { tenderness }\end{array}$ \\
\hline Ghaly and Ring (1999) [17] & 62 & Male & Subcutaneous (supraclavicular) & 1.0 & 20.0 & $\begin{array}{l}\text { Pain, } \\
\text { tenderness, } \\
\text { cold }\end{array}$ \\
\hline Abela et al. (2000) [14] & 52 & Male & Subcutaneous & 1.5 & 10.0 & $\begin{array}{l}\text { Pain, } \\
\text { tenderness }\end{array}$ \\
\hline Solivetti et al. (2002) [18] & 58 & Male & NR & 0.4 & 1.0 & NR \\
\hline Schiefer (2016) - 2 cases [3] & $38 / \mathrm{NR}$ & Male/NR & Subcutaneous (medial scapula)/NR & $0.6 / \mathrm{NR}$ & $2.0 / \mathrm{NR}$ & $\begin{array}{l}\text { Pain, } \\
\text { tenderness/NR }\end{array}$ \\
\hline Boretto et al. (2008) [6] & 54 & Female & Insertion deltoid & NR & 30.0 & $\begin{array}{l}\text { Pain, } \\
\text { tenderness }\end{array}$ \\
\hline Gautam et al. (2008) [31] & 25 & Female & Acromion & NR & 5.0 & $\begin{array}{l}\text { Pain, } \\
\text { tenderness }\end{array}$ \\
\hline Karakurum et al. (2009) [15] & 71 & Male & Posterior fibers deltoid & 2.5 & 0.5 & $\begin{array}{l}\text { Pain, } \\
\text { tenderness, } \\
\text { cold }\end{array}$ \\
\hline Rishi et al. (2012) [11] & 51 & Male & $\begin{array}{l}\text { Subcutaneous posterior scapula } \\
\text { (glomangiosarcoma) }\end{array}$ & 1.0 & 0.165 & Pruritus \\
\hline Proietti et al. (2013) [4] & 30 & Female & Subcutaneous posterior scapula & 4.0 & 1.0 & $\begin{array}{l}\text { Pain, } \\
\text { paresthesia }\end{array}$ \\
\hline Geramizadeh et al. (2015) [13] & 25 & Female & Adjacent clavicle & 4.9 & Since adolescence & $\begin{array}{l}\text { Pain, } \\
\text { tenderness }\end{array}$ \\
\hline Singh et al. (2016) [27] & 70 & Male & Suprascapular notch & NR & 6.0 & $\begin{array}{l}\text { Pain, } \\
\text { tenderness }\end{array}$ \\
\hline Beytemür et al. (2016) [16] & 68 & Male & Anterior fibers deltoid & 3.0 & 1.0 & $\begin{array}{l}\text { Pain, } \\
\text { tenderness }\end{array}$ \\
\hline Ravikanth et al. (2018) [32] & 56 & Male & Subcutaneous (supraclavicular) & $<1.0$ & 4.0 & $\begin{array}{l}\text { Pain, } \\
\text { tenderness }\end{array}$ \\
\hline Present case & 61 & Male & Posterior fibers, deltoid & 1.0 & 1.0 & $\begin{array}{l}\text { Pain, } \\
\text { tenderness }\end{array}$ \\
\hline
\end{tabular}

NR: nonregistered; NA: not available.

curative treatment with marginal excision. Free margins were confirmed by histology which, furthermore, excluded other aspects of malignancy in the lesion.

Surgery outcome is excellent [3], with prompt disappearance of the symptoms after excision [12]. There are no documented cases of recurrence around the shoulder.

The atypical location, the usual small-size of the lesions, and deeper locations explain why these lesions are frequently overlooked on common imaging exams such as simple ultrasonography, accounting for the delay in diagnosis. In our case, despite being small in size, the lesion was fortunately identified on ultrasonography which prompted further investigation. The fact that full recovery is expected after adequate treatment further emphasis the needs to raise awareness for this pathology when considering causes of chronic shoulder pain.

\section{Conclusion}

Glomus tumors around the shoulder seem less rare than what was previously believed and should therefore be included in the differential diagnosis of unexplained shoulder 
pain. MRI may help confirm diagnosis in a high suspicious clinical setting. Surgery with marginal excision is usually curative, and excellent clinical outcome is expected.

\section{Data Availability}

Data can be available on request. To request the data, please contact the corresponding author: Luís Pedro Vieira (address: Alameda Professor Hernâni Monteiro, Serviço Ortopedia e Traumatologia Centro Hospitalar S. João, 4200 Porto, Portugal; email: luisppvieira@gmail.com).

\section{Conflicts of Interest}

The authors declare that they have no conflicts of interest.

\section{References}

[1] C. D. M. Fletcher, World Health Organization, International Agency for Research on Cancer. WHO Classification of Tumours of Soft Tissue and Bone. 4, IARC Press, Lyon, France, 2013.

[2] G. P. Maxwell, R. M. Curtis, and E. F. Wilgis, "Multiple digital glomus tumors," Journal of Hand Surgery, vol. 4, no. 4, pp. 363-367, 1979.

[3] T. K. Schiefer, W. L. Parker, O. A. Anakwenze, P. T. Amadio, C. Y. Inwards, and R. J. Spinner, "Extradigital glomus tumors: a 20-year experience,” Mayo Clinic Proceedings, vol. 81, no. 10, pp. 1337-1344, 2006.

[4] A. Proietti, G. Alì, F. Quilici, P. Bertoglio, A. Mussi, and G. Fontanini, "Glomus tumor of the shoulder: a case report and review of the literature," Oncology Letters, vol. 6, no. 4, pp. 1021-1024, 2013.

[5] Z. Gombos and P. J. Zhang, "Glomus tumor," Archives of Pathology \& Laboratory Medicine, vol. 132, no. 9, pp. 14481452, 2008.

[6] J. G. Boretto, C. Lazerges, B. Coulet, P. Baldet, and M. Chammas, "Calcified glomus tumor of the shoulder. A case report," Chirurgie de la Main, vol. 27, no. 4, pp. 183-186, 2008.

[7] S. D. Heys, J. Brittenden, P. Atkinson, and O. Eremin, "Glomus tumour: an analysis of 43 patients and review of the literature," The British Journal of Surgery, vol. 79, no. 4, pp. 345-347, 1992.

[8] J. Kolaczek, "Ueber das angio-sarkom," Dtsch Z Chir, vol. 9, no. 3-4, pp. 165-227, 1878.

[9] M. Mravic, G. LaChaud, A. Nguyen, M. A. Scott, S. M. Dry, and A. W. James.

[10] R. C. Akgün, U. Ö. Güler, and U. Onay, "A glomus tumor anterior to the patellar tendon: a case report," Acta Orthopaedica et Traumatologica Turcica, vol. 44, no. 3, pp. 250-253, 2010.

[11] A. Rishi, F. Dulanto, and S. Chen, "Glomangiosarcoma in the shoulder of a 51-year-old man," Dermatol Pract Concept, vol. 2, no. 1, pp. 49-51, 2012.

[12] J. P. Heiney and M. C. Leeson, "Unique size and location of a glomus tumor with a review of the literature," Journal of Shoulder and Elbow Surgery, vol. 18, no. 1, pp. e1-e3, 2009.

[13] B. Geramizadeh, A. Khorshidi, and H. Hodjati, "Chronic long standing shoulder pain, caused by glomus tumor," Rare Tumors, vol. 7, no. 2, pp. 37-39, 2015.

[14] M. Abela, A. S. Cole, G. A. Hill, and A. J. Carr, "Glomus tumor of the scapular region," Journal of Shoulder and Elbow Surgery, vol. 9, no. 6, pp. 532-533, 2000.
[15] G. Karakurum, E. Tutar, L. Pirbudak, and A. Mizrak, "Glomus tumour of the deltoid muscle. A case report," Acta Orthopaedica Belgica, vol. 75, no. 5, pp. 681-683, 2009.

[16] O. Beytemür, O. Adanır, U. S. Tetikkurt, and M. A. Güleç, "Glomus tumor located in deltoid muscle," Acta Orthopaedica et Traumatologica Turcica, vol. 50, no. 2, pp. 242-244, 2016.

[17] R. F. Ghaly and A. M. Ring, "Supraclavicular glomus tumor, 20 year history of undiagnosed shoulder pain: a case report," Pain, vol. 83, no. 2, pp. 379-382, 1999.

[18] F. M. Solivetti, M. F. Thorel, C. Cota, P. Donati, and E. Faloni, "Ultrasound pattern of glomus tumor of the shoulder," $\mathrm{La}$ Radiologia Medica, vol. 104, no. 5-6, pp. 481-483, 2002.

[19] O. T. Bailey, "The cutaneous glomus and its tumors-glomangiomas," The American Journal of Pathology, vol. 11, pp. 915-936, 1935.

[20] G. Yoshikawa, M. Murakami, M. Ishizawa, K. Matsumoto, and S. Hukuda, "Glomus tumor of the musculotendinous junction of the rotator cuff," Clinical Orthopaedics and Related Research, vol. 326, pp. 250-253, 1996.

[21] S. N. Roberts, C. Carter, J. N. Brown, M. G. Hayes, and A. Saies, "Enormous glomus tumor of the shoulder," Journal of Shoulder and Elbow Surgery, vol. 8, no. 4, pp. 365-366, 1999.

[22] H. Giele, "Hildreth's test is a reliable clinical sign for the diagnosis of glomus tumours," Journal of Hand Surgery, vol. 27, no. 2, pp. 157-158, 2002.

[23] T. Chou, S. C. Pan, S. J. Shieh, J. W. Lee, H. Y. Chiu, and C. L. Ho, "Glomus tumor," Annals of Plastic Surgery, vol. 76, Supplement 1, pp. S35-S40, 2016.

[24] S. H. Chen, Y. L. Chen, M. H. Cheng, K. M. Yeow, H. C. Chen, and F. C. Wei, "The use of ultrasonography in preoperative localization of digital glomus tumors," Plastic and Reconstructive Surgery, vol. 112, no. 1, pp. 115-119, 2003.

[25] M. M. al-Qattan, A. al-Namla, A. al-Thunayan, F. al-Subhi, and A. F. el-Shayeb, "Magnetic resonance imaging in the diagnosis of glomus tumours of the hand," Journal of Hand Surgery, vol. 30, no. 5, pp. 535-540, 2005.

[26] A. L. Folpe, J. C. Fanburg-Smith, M. Miettinen, and S. W. Weiss, "Atypical and malignant glomus tumors. Analysis of 52 cases, with a proposal for the reclassification of glomus tumors," The American Journal of Surgical Pathology, vol. 25, no. 1, pp. 1-12, 2001.

[27] R. Singh, A. Malhotra, G. Cribb, P. Cool, and S. Hay, "Unusual lesions mimicking impingement syndrome in the shoulder joint - think medially," Annals of Medicine and Surgery, vol. 10, pp. 88-91, 2016.

[28] M. Riveros and G. T. Pack, "The glomus tumor; report of 20 cases," Annals of Surgery, vol. 133, no. 3, pp. 394-400, 1951.

[29] E. W. Massey, "Shoulder pain from glomus tumour," Journal of Neurology, Neurosurgery, and Psychiatry, vol. 55, no. 5, pp. 413-414, 1992.

[30] E. Calonje and C. D. M. Fletcher, "Cutaneous intraneural glomus tumor," The American Journal of Dermatopathology, vol. 17, no. 4, pp. 395-398, 1995.

[31] V. K. Gautam, P. K. Agarwal, L. Maini, and A. Prakash, "Intraosseous glomus tumor in acromion process of scapula," Orthopedics, vol. 31, no. 4, p. 406, 2008.

[32] R. Ravikanth and A. Nagotu, "Glomus tumor with rare clinical presentation as chronic shoulder pain," Tzu Chi Medical Journal, vol. 30, no. 1, pp. 51-52, 2018. 